\title{
Asthma and exercise-induced respiratory disorders in athletes. The position paper of the Polish Society of Allergology and Polish Society of Sports Medicine
}

\author{
Radoslaw Gawlik', Marcin Kurowski², Marek Kowalski², Ziemowit Ziętkowski ${ }^{3}$, \\ Andrzej Pokrywka ${ }^{4,5}$, Hubert Krysztofiak ${ }^{5,6}$, Jarosław Krzywański ${ }^{5,7}$, Andrzej Bugajski ${ }^{5,8}$, \\ Zbigniew Bartuzi ${ }^{9}$ \\ 'Department of Internal Diseases, Allergy and Clinical Immunology, Medical University of Silesia, Katowice, Poland \\ ${ }^{2}$ Department of Immunology and Allergy, Medical University of Lodz, Lodz, Poland \\ ${ }^{3}$ Department of Allergology and Internal Medicine, University of Bialystok, Bialystok, Poland \\ ${ }^{4}$ Department of Applied and Clinical Physiology, Faculty of Medicine and Health Sciences, \\ University of Zielona Gora, Zielona Gora, Poland \\ ${ }^{5}$ Polish Society of Sports Medicine \\ ${ }^{6}$ Department of Applied Physiology, Mossakowski Medical Research Centre, Polish Academy of Sciences, \\ Warsaw, Poland \\ ${ }^{7}$ National Centre for Sports Medicine, Warsaw, Poland \\ ${ }^{8} \mathrm{Higher}$ School of Physiotherapy, Wroclaw, Poland \\ ${ }^{9}$ Department of Allergy, Clinical Immunology and Internal Medicine, Collegium Medicum in Bydgoszcz, \\ Nicolaus Copernicus University in Torun, Poland
}

Reprint: Gawlik R, Kurowski M, Kowalski M, Ziętkowski Z, Pokrywka A, Krysztofiak H, Krzywański J, Bugajski A, Bartuzi Z. Asthma and exercise-induced respiratory disorders in athletes. The position paper of the Polish Society of Allergology and Polish Society of Sports Medicine. Adv Dermatol Allergol 2019; 36: 1-10. DOI: https://doi.org/10.5114/ada.2019.82820.

\section{ABSTRACT}

Exercise-induced respiratory symptoms describe acute airway narrowing that occurs as a result of exercise. It includes exercise-induced bronchoconstriction (EIB) and exercise-induced asthma (EIA) issues. To provide clinicians with practical guidelines, a multidisciplinary panel of stakeholders was convened to review the pathogenesis of EIB/EIA and to develop evidence-based guidelines for the diagnosis and treatment. Recommendations for the diagnosis and treatment of EIB were developed. High-intensity exercise in polluted environment (cold air, humidity, contamination, allergens) may increase the risk of EIB and asthma symptoms in athletes. Diagnostic procedures should include history taking, physical examination, atopy assessment and functional tests of the respiratory system. A strong recommendation was made for regular use of inhaled glucocorticosteroids and avoidance of short-acting $\beta_{2}$-agonists as the only treatment. The treatment of asthma in athletes should always take into account current anti-doping regulations. This position paper reflects the currently available evidence.

KEY WORDS:

exercise-induced bronchoconstriction, diagnosis, treatment. 


\section{ADDRESS FOR CORRESPONDENCE:}

Radoslaw Gawlik, Department of Internal Diseases, Allergy and Clinical Immunology, Medical University of Silesia, 35 Ceglana St, 40-514 Katowice, Poland, phone: +48 601464 786, e-mail: radwags@poczta.onet.pl

\section{EPIDEMIOLOGY OF EXERCISE-INDUCED ASTHMA/EXERCISE-INDUCED BRONCHO CONSTRICTION}

Exercise-induced respiratory symptoms are most frequently referred to as:

- exercise-induced bronchoconstriction (EIB) or

- exercise-induced asthma (EIA).

Both terms were often used interchangeably in the past. Currently it is recommended to describe exerciseinduced symptoms in people without coexisting asthma and allergies as exercise-induced bronchoconstriction whereas exercise-induced asthma should be referred to as post-exercise bronchoconstriction in asthma sufferers.

Bronchoconstriction is a form of bronchial hyperreactivity which is defined as increased readiness of the bronchi to constrict in response to a variety of external factors. Bronchial hyperreactivity is the basic feature of bronchial asthma and it occurs more often in athletes than in general population, especially in swimmers and winter sports athletes $[1,2]$.

There is an extensive literature on the prevalence of asthma or EIB symptoms in competitive athletes. Exercise-induced asthma symptoms were identified in over 11\% of the USA representatives at the Summer Olympic Games in Los Angeles (1984). The observation was confirmed by the studies conducted 12 years later at the Olympic Games in Atlanta [3]. In the USA team at the Winter Olympic Games in Nagano (1998), as many as 22\% of the athletes had previously been diagnosed with asthma and over $18 \%$ had used antiasthmatic medications before $[4,5]$. European studies carried out since 2000 have reported a gradual increase in the incidence of asthma and allergy symptoms in athletes [6-9].

When Polish athletes participating in the Olympic Games in Beijing (2008) responded to a questionnaire, $28.4 \%$ of them reported at least one symptom of exercise-induced asthma (coughing, shortness of breath, tightening of the chest or wheezing). No differences in asthma symptoms incidence were observed between endurance and non-endurance sports. Clinical evaluation confirmed the diagnosis of asthma in $11.3 \%$ of the examined athletes. It is noteworthy that prior to the study inclusion, asthma was diagnosed in $5.9 \%$ of the athletes only and $8.6 \%$ declared ever taking anti-asthmatic medication, either $\beta_{2}$-agonists or glucocorticosteroids or leukotriene receptor antagonists [10].
The examination of the Olympic athletes representing Norway, Germany and Spain in Beijing showed an increased risk of symptoms typical of asthma as well as asthma diagnosis by a medical specialist in endurance and water sports athletes [11].

Swimmers represent a group of athletes with a higher risk of the development of exercise-induced asthma symptoms [11-15]. Although swimming is recommended for asthma sufferers to improve their respiratory system functioning, regular swimming may increase the probability of asthma in healthy people. Theoretically, humid and warm environment of most swimming pools should prevent the airway mucosa from drying and cooling. We should bear in mind, however, that exposure to chlorine compounds, mites and mould spores is associated with potential asthma. Skating and cross-country skiing are the kinds of winter sports which are connected with a higher incidence of such symptoms as coughing and dyspnoea. These symptoms are ascribed to the exposure of the airways to adverse conditions or irritating chemical compounds released from the ice [16-21].

\section{PATHOGENESIS}

Asthma is a heterogeneous disease typically associated with a chronic respiratory inflammation which is defined as a syndrome of such respiratory symptoms as wheezing, dyspnoea, chest tightening and coughing which differ in time and intensity and are connected with variable airways obstruction.

Currently discussed pathogenic mechanisms potentially responsible for exercise-induced bronchoconstriction in people who practice high-intensity exercise on a regular basis include [22]:

- osmotic and thermal changes in airways mucosa caused by exercise-induced hyperventilation (osmotic and thermal hypothesis);

- damage to respiratory epithelium;

- increasing severity of the airway inflammation;

- neural activation.

Osmotic and thermal changes to bronchial mucosa are the rationale behind the osmotic and thermal hypotheses which are considered as 'classical' ones in the attempts to explain the pathogenesis of EIB in athletes. Increased water evaporation from the mucosa during exercise leads to the increase in the osmolarity of the fluid covering the respiratory epithelium. The changes 
to osmotic relations result in the lysis of the cells and the release of the mediators including cysteinyl leukotrienes which have strong bronchoconstrictive properties. Furthermore, the airway cooling activates cholinergic receptors, which causes increased tension of bronchial smooth muscles and enhanced fluid secretion in airways. Directly after exercise completion the respiratory tract warming commences and leads to secondary hyperaemia and increased capillary permeability in the bronchial wall.

A rise in the number of inflammatory cells (eosinophils, neutrophils, epithelial cells) has been observed in the respiratory tract of athletes. A large body of evidence has already proven that damage to respiratory epithelium during exercise (particularly in adverse environmental conditions) significantly increases susceptibility to EIB. The conclusions mentioned above were drawn from the analyses of the markers of respiratory epithelium damage (e.g. protein CC16) [23-25]. Unfavourable and harmful environmental conditions for exercise can also contribute to respiratory tract damage and increased susceptibility to EIB. The most spectacular associations were found in the relations between exposure to chlorine compounds (trichloramine) while swimming and the increase in bronchial hyperreactivity (BHR) [12-14, 24-27]. Exposure to dry and cold air while practicing endurance winter sports can be another factor which increases the risk of EIB $[16,28]$. Some other studies, however, do not provide results which are compelling enough to significantly associate exercise in adverse conditions with predisposition to EIB. It is suggested that damage to respiratory epithelium occurs only in the presence of BHR symptoms or exercise-induced bronchoconstriction. Consequently, mutual causation and the sequence of the described phenomena are still open to discussion.

The innervation of the respiratory tract is mainly composed of parasympathetic fibres. Stimulation of parasympathetic cholinergic fibres results in bronchoconstriction. In the light of the recent research, high-intensity exercise is thought to magnify para-sympathomimetic activity, thereby increasing the tension of bronchial smooth muscles and, consequently, increasing the probability of EIB. The relationship between BHR and some autonomic nervous system-dependent responses, e.g. perspiration, tearing, saliva production, have been reported. However, although chronically enhanced parasympathomimetic nervous system activity is observed there are data which do not confirm the correlation between BHR and dysfunctional autonomic regulation. Some authors suggest that autonomic modulation may be involved in BHR development but only when accompanied by the risk of inspiring harmful components of the air $[1,29,30]$.
Neurogenic inflammation is also considered in the investigation of EIB pathogenesis [31]. High-intensity exercise elevates the concentration of substance $P$ which is one of the key mediators of neurogenic inflammation. Acetylcholine and nerve growth factor (NGF) have also been put forward as potentially involved in the development of the EIB-provoking inflammation.

Since none of the aforementioned mechanisms fully explains the pathogenesis of EIB, potential interaction of several mechanisms should be taken into account while assessing individual predisposition to exercise-induced respiratory symptoms. The identification of the athletes susceptible to EIB appears to be the key issue here as it may contribute to the improvement of preventive measures.

The observations made within the last 20-30 years indicate that the asthma rate is higher in athletes, especially those practicing endurance sports. The risk of asthma in the athletes with atopy symptoms is several times higher than in healthy population [7].

\section{DIAGNOSTIC PROCEDURES}

Diagnostic procedures in the case of suspected asthma in athletes (when they report exercise-related respiratory problems) should include:

- thorough history including exercise-related problems and comorbidities;

- physical examination with an emphasis on the respiratory system, symptoms of allergic origin and the assessment of any comorbidities which should be taken into account in differential diagnosis;

- assessment of atopic origin (allergy skin tests for inhalants, specific IgE, total IgE) and assessment of the inflammatory process which is typical of asthma (exhaled nitric oxide);

- basic diagnostic tests: morphology with blood smear (eosinophils), C-reactive protein, chest X-ray evaluation;

- functional evaluation of the respiratory system with spirometry, reversible obstruction test, assessment of the reactivity of the bronchial tree in direct challenges (nonspecific bronchoprovocation test with methacholine) - examination taking into account individual indications and contraindication;

- exercise test;

- if the assessment of the cardiovascular system is required, electrograpohy (ECG), echocardiography, Holter monitoring of the heart activity and arterial blood pressure (individually selected).

It should be noted that a weak correlation between the symptoms and the results of the pulmonary function test is not uncommon in athletes. 


\section{MEDICAL HISTORY DATA}

Clinical symptoms of asthma in athletes include coughing (frequently as a sole or dominating symptom), wheezing, chest tightness, 'shortage of breath' or excessive mucus secretion after short, several-minute, continuous exercise. Asthma in athletes can also be manifested by chest pain, 'locker room cough' and lower level of exercise tolerance. Avoiding physical activity and inability to keep up with the peers are also characteristic features $[8,32,33]$.

Functional evaluation of the respiratory system is a crucial element in asthma diagnosis. The evaluation should begin with initial spirometry. The procedures which will follow are dependent on the spirometry results and potential obturation [34].

In the case of bronchial tree obstruction, the bronchial reversibility test should be performed (BRT). It should be remembered that normal results of the spirometry test do not exclude reversible obstruction testing and its positive outcomes.

The bronchial reversibility test estimates the ventilation parameters, primarily forced expiratory volume in $1 \mathrm{~s}\left(\mathrm{FEV}_{1}\right)$ and forced vital capacity (FVC) at 10-20 min after inhalation of $400 \mu \mathrm{g}$ salbutamol. The increase in $\mathrm{FEV}_{1}$ and/or FVC by over $12 \%$ and by over $200 \mathrm{ml}$ in comparison to baseline values is regarded as a positive result.

The reversible obstruction test is a method of high specificity and low sensitivity. It identifies negative results in people with normal ventilation indices as well as in patients with significantly decreased indices of ventilation as a consequence of bronchial remodelling. Negative results can also be obtained in patients with inflammatory changes but the ventilation parameters can be improved significantly after several weeks of glucocorticosteroids administration.

The correct performance of BRT depends on careful spirometry and medication administration: 4 single doses of salbutamol $(4 \times 100 \mu \mathrm{g})$ using the inhalation chamber (air completely exhaled, then inhalation of one dose to total lung capacity (TLC), the air held for 5-10 s before exhaling and 30-second intervals between doses). Smaller doses can be applied in children or when side effects (tachycardia, tremor) occur. Salbutamol can be replaced by other drugs e.g. ipratropium bromide $(4 \times 40 \mu \mathrm{g})$. The spirometry test is repeated after $15 \mathrm{~min}$ for short-acting $\beta_{2}$-agonist (SABA) and 30 min for short acting muscarinic antagonist (SAMA), which terminates the evaluation. The test is considered positive at $\mathrm{FEV}_{1}$ and/or FVC change $>200 \mathrm{ml}$ and $12 \%$ of the initial value [35].

When spirometry values fall into the normal range, the diagnostic steps should include the assessment of bronchial hyperactivity by bronchial provocation tests (BPT) [36].

Bronchial hyperreactivity refers to excessive bronchoconstrictive reaction to specific and non-specific stimuli which normally do not cause such a response. Bronchial hyperreactivity can be characterised by respiratory symptoms such as cough, wheeze and dyspnoea and it is assessed by bronchial provocation tests. Clinical practice employs direct and indirect methods. Indirect methods are more specific for asthma whereas direct ones are more sensitive in BHR identification [36].

In direct methods the constriction results from a direct stimulation of the receptors on muscle fibres; methacholine activates muscarinic M3 receptors, histamine activates postsynaptic $\mathrm{H} 1$ receptors. The result is expressed as methacholine or histamine concentration which causes $\mathrm{FEV}_{1}$ decline by $20 \%$ in comparison to the baseline value [36].

In indirect methods the bronchoconstriction is induced by degranulation of mast cells and activation of other inflammatory cells (eosinophils) triggered by a substance or factor which releases the mediators responsible for the constriction of bronchial smooth muscles. Indirect methods include the exercise test, hyperventilation test with carbon dioxide-enriched air (EVH) and hypertonic saline or mannitol provocation tests $[37,38]$.

The International Olympic Committee (IOC) established asthma diagnostic criteria and approval criteria for the use of inhaled anti-asthmatics (including $\beta_{2}$-agonists) by athletes. The criteria include the symptoms suggestive of asthma in history and a positive outcome of at least one of the following tests [32]:

- positive reversibility test outcome $\left(\mathrm{FEV}_{1}\right.$ increased by $\geq 12 \%$ and $\geq 200 \mathrm{ml}$ );

- positive exercise test results (temp. $20-25^{\circ} \mathrm{C}$, humidity $40-50 \%$ ) or positive result of eucapnic voluntary hyperventilation with $\mathrm{CO}_{2}$-enriched air test $(\mathrm{EVH})-$ decline in $\mathrm{FEV}_{1} \geq 10 \%$;

- positive nonspecific bronchoprovocation test with methacholine: $\mathrm{PC}_{20} \leq 4 \mathrm{mg} / \mathrm{ml}$ for athletes not taking inhaled glucocorticosteroids or $\mathrm{PC}_{20} \leq 16 \mathrm{mg} / \mathrm{ml}$ for athletes taking inhaled glucocorticosteroids $>1$ month;

- positive result of the hypertonic saline or mannitol provocation test (decrease in $\mathrm{FEV}_{1} \geq 15 \%$ ).

Basic diagnostic procedures also include the exercise test after considering the indications and contraindications for such testing. It should be pointed out that the exercise test outcomes are affected by a range of factors, such as the conditions (the air temperature and humidity) and the exercise type (treadmill or cycle ergometer).

The patient qualified for exercise testing should undergo the spirometry test with $\mathrm{FEV}_{1}$ assessment prior to, directly after and at 1, 5, 10,15, 30 min after exercise completion (acceptable time modifications accor- 
ding to the patient's status). The test objective is to achieve $75-85 \%$ of maximal load and its maintenance for 6-8 $\mathrm{min}$. Seven-nine min is the optimal duration of the exercise test. Maximal load is defined as the exercise which does not cause further increase in oxygen intake. The type of exercise load protocols depends on the laboratory, the patient's age, fitness level and comorbidities. Common guidelines, however, recommend that the patient should breathe through the mouth (clip on the nose) with the air temperature of $20-25^{\circ} \mathrm{C}$ and humidity below $50 \%$.

The exercise load should be increased and lead to $40-60 \%$ of predicted maximal voluntary ventilation within the first $2-3 \mathrm{~min}$ (initial value: $\mathrm{FEV}_{1} \times 35$ ) or $80-90 \%$ of the predicted maximal heart rate $(\mathrm{HR}=220$ - age in years) [39]. Nevertheless, in well-trained athletes the recommended exercise load values may be insufficient. In justified cases, the conditions of the given athlete's sports discipline should be considered as the exercise testing venue [40].

Exhaled nitric oxide assessment $\left(\mathrm{F}_{\mathrm{ENO}}\right)$ is an easy and non-invasive diagnostic study. An increased expression of inducible nitric oxide synthase and elevated $\mathrm{F}_{\mathrm{ENO}}$ level have been demonstrated in asthma sufferers. $\mathrm{F}_{\mathrm{ENO}}$ is an inflammation-sensitive marker which responds quickly to implemented treatment as well as to disease exacerbation and in asthmatic patients it correlates well with the indices of the inflammatory process connected with eosinophilic infiltration. The contribution of $\mathrm{F}_{\mathrm{ENO}}$ measurements in monitoring the treatment with inhaled steroids should not be underrated $[41,42]$. The identification of increased exhaled nitric oxide values (over $25 \mathrm{ppb}$ - mild, over 35 ppb - moderate, over 50 ppb - high) in athletes displaying typical exercise-induced asthma symptoms has a high predictive value in asthma diagnosis.

Each case should be analysed individually and in case of diagnostic doubts, indistinctive symptoms or no desirable treatment results, differential diagnosis is advisable $[32,33]$ and should include:

- cardiovascular diseases (heart diseases, ischemic heart disease, arterial hypertension), respiratory diseases (eosinophilic pulmonary diseases, chronic bronchitis, tuberculosis);

- chronic pulmonary embolism;

- chronic sinusitis and inflammation of nasal mucosa;

- exercise-induced laryngeal dysfunction (abnormal larynx response to physical exercise) manifested by inspiratory dyspnoea and exercise-induced inspiratory stridor. The symptoms occur during exercise and subside 5 min after exercise completion;

- gastroesophageal reflux disease, which may be the underlying cause of exercise-induced respiratory symptoms and may coexist with vocal fold dysfunction;
- exercise-induced hyperventilation (a pseudo-asthma syndrome), which may be connected with hypocapnia and potentially with exercise-induced disturbances in respiratory homeostasis;

- exercise-induced anaphylaxis. Predisposing factors of exercise-induced anaphylaxis include: food consumption (wheat 57\%, shrimps 17\%, crabs, nuts, grapes, buckwheat, fish, tomatoes, celery, egg white) most commonly within the first $4 \mathrm{~h}$ before exercise, acetylsalicylic acid (ASA), non-steroid anti-inflammatory drugs (NSAIDs), alcohol, fatigue, infection, stress. American studies reported that 5-15\% of anaphylaxes in children were induced by exercise.

\section{TREATMENT}

Treatment of asthma in athletes should be provided in accordance with the current guidelines on asthma management preserving the specific needs of asthmatic patients. The guidelines have been developed by the Global Initiative for Asthma and they describe the aims of successful treatment as follows:

- achievement and maintenance of symptoms control;

- prevention of exacerbation;

- maintenance of the respiratory function at close to normal parameters;

- maintenance of everyday activity including physical exercise.

The objective of asthma management in athletes includes reduced adverse impact of exercise on the respiratory system, which significantly affects exercise capacity and sports achievements.

On the implementation of asthma treatment one should remember about diverse character of the disease which is closely related to the pathomechanism of respiratory inflammation. Varied asthma phenotypes can be distinguished in athletes, some examples being atopic asthma, accompanied by other allergies, or exercise-induced respiratory symptoms and bronchial hyperreactivity (BHR) unrelated to allergy but related to the specific environment [43]. Respiratory tract inflammation is the primary cause of the disease symptoms, therefore early anti-inflammatory intervention with inhaled glucocorticosteroids is crucial and indispensable in asthma management in athletes. Bronchodilators (SABA, long-acting $\beta$-agonists (LABA)) should not be applied as the sole medication. The treatment must be adjusted to the symptoms severity. In order to fully control the disease and to reduce the risk of asthma exacerbation, several intensity degrees of asthma therapy have been suggested [42].

Inhaled glucocorticosteroids are basic medicines in chronic therapy yet they are too infrequently applied by 
TABLE 1. Daily doses of inhaled glucocorticosteroids according to GINA 2017

\begin{tabular}{|l|c|c|c|}
\hline \multirow{2}{*}{ Medication } & \multicolumn{3}{|c|}{ Daily dose [ug] } \\
\cline { 2 - 4 } & Low & Medium & High \\
\hline Betamethasone dipropionate (CFC - suspension) & $200-500$ & $>500-1000$ & $>1000$ \\
\hline Betamethasone dipropionate (HFA - solution) & $100-200$ & $>200-400$ & $>400$ \\
\hline Budesonide (DPI) & $200-400$ & $>400-800$ & $>800$ \\
\hline Ciclesonide (HFA - solution) & $80-160$ & $>160-320$ & $>320$ \\
\hline Fluticasone furoate (DPI) & 100 & N/A & N/A \\
\hline Fluticasone propionate (DPI) & $100-250$ & $>250-500$ & $>500$ \\
\hline Fluticasone propionate (HFA - suspension) & $100-250$ & $>250-500$ & $>500$ \\
\hline Mometasone furoate & $110-220$ & $>440-880$ & $>880$ \\
\hline Triamcinolone acetonide & $400-1000$ & $>1000-2000$ & $>2000$ \\
\hline
\end{tabular}

athletes [44]. They should be used in appropriate doses at the earliest stage possible.

Doses of inhaled glucocorticosteroids are determined by the degree of symptoms severity. Daily doses of in-

TABLE 2. Short-acting $\beta$-agonists (SABA) and long-acting $\beta$-agonists $(\mathrm{LABA})$ are used in asthma management

\begin{tabular}{|c|}
\hline Short-acting $\beta$-agonists: \\
\hline Bitolterol - Tornalate \\
\hline Fenoterol - Berotec \\
\hline Isoprenaline/isoproterenol - Isuprel \\
\hline Levosalbutamol/levalbuterol - Xopenex \\
\hline Orciprenaline/metaproterenol - Alupent \\
\hline Pirbuterol - Maxair \\
\hline Salbutamol/albuterol - Ventolin \\
\hline Terbutaline - Bricanyl \\
\hline Long-acting $\beta$-agonists: \\
\hline Arformoterol - Brovana \\
\hline Bambuterol - Bambec, 0xeol \\
\hline Clenbuterol - Dilaterol, Spiropent \\
\hline Formoterol - Foradil, 0xis \\
\hline Salmeterol - Serevent \\
\hline Ultra-long acting $\beta_{2}$-agonists (ultra-LABA): \\
\hline Abediterol \\
\hline Carmoterol \\
\hline Indacaterol - Arcapta Neohaler (U.S.), Onbrez Breezhaler (EU, RU) \\
\hline Olodaterol - Striverdi Respimat \\
\hline Vilanterol: \\
\hline with umeclidinium bromide - Anoro Ellipta \\
\hline $\begin{array}{l}\text { with fluticasone furoate - Breo Ellipta (U.S.), Relvar Ellipta } \\
(E U, R U)\end{array}$ \\
\hline
\end{tabular}

haled glucocorticosteroids according to GINA 2017 are shown in the Table 1.

Occasionally, for various reasons, inhaled glucocorticosteroids are less effective in asthma control in competitive athletes. Hoshino et al. reported ineffectiveness of therapy with inhaled glucocorticosteroids in $16.3 \%$ of 80 asthmatic athletes [45].

Apart from anti-inflammatory activity, glucocorticosteroids reduce the dose of required $\beta$-mimetics, diminish $\beta$-mimetics tolerance and, what is of particular value, decrease bronchial reactivity (to exercise, cold, allergens). It may be concluded that when SABA application is necessary more often than twice a week, the therapy should include regular inhaled glucocorticosteroids applied in small doses. Infrequently, in case of asthma exacerbation, glucocorticosteroids are applied orally.

Mild symptoms can be managed by leukotriene receptor antagonists (LTRAs) (montelukast). Antileukotriene drugs weaken exercise-induced bronchoconstriction and protect against environmental contaminants [46, 47]. Chronic application of antileukotriene drugs have been proven to be effective in prevention of sudden exercise-induced dyspnoea $[48,49]$. Reduction of the applied dose of inhaled glucocorticosteroids may be facilitated by inclusion of LTRA. Similar effects are produced by allergen immunotherapy applied in patients allergic to house dust mites.

\section{$\beta_{2}$-MIMETICS}

Owing to their quick and effective bronchodilating properties, $\beta_{2}$-mimetics are the most frequently used medications in asthma management. They prevent sudden dyspnoea when applied 5-10 min prior to exercise. Short-acting $\beta$-agonists and long-acting $\beta$-agonists are used in asthma management (Table 2).

The above-mentioned medications are not recommended in monotherapy as they can increase the risk 
of acute dyspnoea [50]. When pro re nata (PRN) SABA application is required more often than 2 times per week, inhaled glucocorticosteroids in minimal doses should be included in the therapy.

When applied systematically as the exclusive medication, $\beta$-adrenergic agonists increase bronchoconstrictive responsiveness of airways to exercise and allergens, augment BHR (if they are not applied prior to exercise) and decrease their effectiveness when applied PRN in sudden dyspnoea [51].

Regular application of $\beta_{2}$-agonists in monotherapy can also lead to the drug tolerance which will reduce their protective and bronchodilatory properties. $\beta$-Mimetics applied in therapeutic doses do not affect the athlete's exercise performance [51].

Anticholinergic drugs can be selected out of other bronchodilators and applied in specific asthma patients. They are of particular use in the athletes who display increased parasympathetic tone [30].

Atopic athletes who suffer from rhinitis or conjunctivitis triggered by exposure to allergens should use antihistamines. Allergen immunotherapy is a method of choice for people allergic to pollen and home dust mite. Desensitization modifies the course of disease, relieves the symptoms, prevents new allergies and reduces the dosage of applied inhaled glucocorticosteroids [52, 53].

The available literature reports protective properties of cromones in exercise-induced bronchoconstriction [54]. Yet, they are infrequently used since other, more effective and rapidly activated and long-lasting agents, are more easily available.

One must not forget about successful treatment of concomitant diseases including upper respiratory tract diseases and, so called, common colds [55].

The usefulness of vitamin D application and supplementation with omega-3 poly-unsaturated fatty acid (PUFA), colostrum, probiotics and selected antioxidants is subject to discussion $[56,57]$.

It is extremely important that asthma sufferers should be educated on the correct drug application (inhalation technique), the recognition of the disease exacerbation and appropriate modification to their therapy. The patients should be provided with the treatment plan and their comprehension and compliance should be controlled regularly, particularly at the onset of the therapy. Regrettably, a large number of athletes do not comply with medical recommendations [58].

\section{NON-PHARMACOLOGICAL TREATMENT}

There are numerous factors which have an influence on undisturbed respiratory functioning and they include, first and foremost, environmental factors such as air tem- perature, humidity and quality in terms of its content of allergens, irritating agents and contaminants.

Therefore, along with pharmacological treatment, asthma sufferers, and athletes in particular, should reduce their exposure to the aforementioned agents.

Exercise should be performed only when asthma is stable and well controlled. Exercise should always be preceded by a warm-up and, so called, 'cold start' ought to be avoided.

Exercising in the company of another person is advisable. It is also recommended that the exercise intensity should be gradually reduced towards the end of training (opposite to warm-up).

Fluids should be frequently replenished in order to avoid dehydration.

When exercising in low temperatures, the use of the protective mask should be considered.

The air warming mask proves effective in prevention of exercise-induced bronchoconstriction triggered by cold air. It enhances humidity of inhaled air and prevents water loss while breathing [59]. Good interpersonal communication between the athlete and his coach and doctor plays an extremely important role in the maintenance of good athletic performance.

To sum up, asthma treatment in athletes is aimed at achieving full control of the disease by self-control, education, monitoring the environmental conditions and by adaptive pharmacotherapy.

\section{ASTHMA TREATMENT AND DOPING}

Correctly performed functional testing allows to confirm asthma diagnosis, select pharmacotherapy and monitor treatment. However, the medications used in asthma therapy, based on $\beta_{2}$-adrenergic agonists and glucocorticosteroids, can also be used for doping purposes. Apart from controlling the basic disease and enabling the continuation of athletic career, the management of asthmatic athletes should also warrant equal opportunities in competition with healthy athletes without the risk of doping suspicions [60]. The opinions on the competition between asthmatic and healthy athletes are still divided. The opinion that the application of some medications by asthma athletes is nothing but doping used for performance enhancement without the risk of disqualification is not unique in the medical circles, too. On the other hand, there have been reported cases of athletes who threatened their health and life by giving up pharmacotherapy, including anti-asthmatics, for fear of suspicions of doping. What is of key importance here is the knowledge of current anti-doping regulations and asthma treatment methods which are permitted by the World Anti-Doping Agency (WADA). 
TABLE 3. List of substances and methods prohibited in sport in $2018^{*}$

\begin{tabular}{|c|}
\hline $\begin{array}{l}\text { Substances and methods prohibited at all times (in- and out-of- } \\
\text { competition): }\end{array}$ \\
\hline SO. Non-approved substances \\
\hline S1. Anabolic agents \\
\hline $\begin{array}{l}\text { S2. Peptide hormones, growth factors, related substances and } \\
\text { mimetics }\end{array}$ \\
\hline S3. $\beta_{2}$-agonists \\
\hline S4. Hormone and metabolic modulators \\
\hline S5. Diuretics and masking agents \\
\hline M1. Manipulation of blood and blood components \\
\hline M2. Chemical and physical manipulation \\
\hline M3. Gene doping \\
\hline $\begin{array}{l}\text { Substances and methods prohibited in-competition (in addition } \\
\text { to categories } S 0 \text { to } S 5 \text { and } M 1 \text { to } M 3 \text { defined above, the follo- } \\
\text { wing categories are prohibited in-competition): }\end{array}$ \\
\hline S6. Stimulants \\
\hline S7. Narcotics \\
\hline S8. Cannabinoids \\
\hline S9. Glucocorticoids \\
\hline Substances prohibited in particular sports: \\
\hline P1. $\beta$-Blockers \\
\hline
\end{tabular}

*Updated and full prohibited list is available on WADA website (www.wada-ama.org).

The list of substances and methods prohibited in sport is one of the prime documents of the World Anti-Doping Programme. Since 2004 WADA has published an annually updated list of methods and substances grouped in three categories i.e.:

- substances and methods prohibited at all times (inand out-of-competition);

- substances and methods prohibited in competition;

- substances and methods prohibited in particular sports (Table 3).

Each athlete has the right to be treated with medications which contain substances that are on the prohibited list. In most cases, however, this is possible only after the formal approval, i.e. after Therapeutic Use Exemption (TUE) has been granted. For that purpose the following criteria must be fulfilled:

- The athlete would experience a significant impairment to health if the prohibited substance or method were to be withheld in the course of treatment.

- The therapeutic use of the prohibited substance or method is unlikely to produce additional enhancement to performance other than that which might be anticipated by a return to normal health following the treatment of a legitimate medical condition.
- There is no reasonable alternative to the use of otherwise prohibited substance or method.

According to anti-doping regulations, however, therapy with some medications which contain substances classified as doping agents is not prohibited. The WADA permits the application of some pharmaceutical substance for medical purposes.

Compounds from two classes on a list of prohibited substances and methods are applied in asthma treatment: $\beta_{2}$-mimetics (category S3) and glucocorticosteroids. Clenbuterol is an exception as, although it is a $\beta_{2}$-mimetic from a pharmacological standpoint, it has been included by WADA in a category of anabolic agents (S1). In accordance with current WADA regulations, athletes are permitted to use inhaled glucocorticosteroids and some $\beta_{2}$-mimetics also as inhalations, i.e. salbutamol (maximum $800 \mu \mathrm{g}$ within $12 \mathrm{~h}$ ), formoterol (maximal daily dose: $54 \mu \mathrm{g}$ ) and salmeterol (maximum $200 \mu \mathrm{g}$ /day). The use of other drug forms (if available) containing the above-mentioned substances or any other medications with $\beta_{2}$-mimetics as well as preparations with glucocorticosteroids applied systemically (orally, intravenously, intramuscularly or per rectum) requires Therapeutic Use Exemption (TUE). The WADA also established that the presence in urine of salbutamol in excess of $1000 \mathrm{ng} / \mathrm{ml}$ or formoterol in excess of $40 \mathrm{ng} / \mathrm{ml}$ is not consistent with the therapeutic use of the substance and will be considered as an Adverse Analytical Finding (AAF) unless the athlete proves, through a controlled pharmacokinetic study, that the abnormal result was the consequence of a therapeutic and permitted dose by inhalation [61]. Such controlled studies allowed to overrule the suspicions of anti-doping rules violation in many cases, especially the cases of inhaled glucocorticosteroids [62]. Nevertheless, it should be strongly emphasised that although formally permitted, the use of preparations of salbutamol, formoterol and salmeterol should be limited to therapeutic applications only.

The list of substances and methods prohibited in sport is an open list. The majority of categories include only examples of doping substances as well as the note that other substances with a similar chemical structure or similar biological effects are also prohibited.

In 2004-2016, WADA published annual versions of the prohibited list with a description of the group of $\beta_{2}$-agonists accompanied by brief information that all the substances from the group are prohibited, including all the optical isomers (e.g. d- and 1-) if they occur. The prohibited list which came into effect on 1 January 2017 listed 11 examples of prohibited $\beta_{2}$-mimetics for the first time. It is common knowledge, however, that this group of compounds is composed of significantly more substances (Table 4) [63]. 
The WADA specified the examples of prohibited glucocorticosteroids for the first time on the list of 1 January 2018 and these included: betamethasone, budesonide, cortisone, deflazacort, dexamethasone, fluticasone, hydrocortisone, methylprednisolone, prednisolone, prednisone, and triamcinolone.

Such a significant change, in comparison with the previous years, was caused by an increasing number of new medications based on a wider range of $\beta_{2}$-mimetics on the one hand, and by the problem of higenamine (also known as norcoclaurine) as an ingredient in dietary and sports supplements on the other. The WADA's intention was to warn against the use of newly appearing antiasthmatic medications but also to attract attention to plan$\mathrm{t}$-derived dietary supplements which may contain doping agents from $\beta_{2}$-agonists. Such ingredients are often omitted in the product description on the label and their consumption may not only result in positive anti-doping tests but also harmful side effects [64, 65]. It should be underlined that it is the athletes' responsibility to make sure that the medication or the supplement they use does not contain prohibited substances.

\section{SUMMARY}

Recently the prevalence of asthma and allergies has been increasing both in general population and in elite athletes. High-intensity exercise in adverse environmental conditions (cold air, humidity, contamination, allergens) may increase the risk of EIB and asthma symptoms in athletes. Asthma and allergies in elite athletes are largely underdiagnosed, which may result from misleading interpretation of exercise-induced symptoms and poor awareness among the athletes, coaches as well as medical staff, of the impact asthma and allergies have on sports performance. Apart from 'classical' hypotheses (osmotic and thermal ones) concerning the pathogenesis of exercise-induced bronchoconstriction and asthma, the involvement of other mechanisms is currently being discussed and these mechanisms include epithelium damage, inflammatory process exacerbation induced by regular, high-intensity exercise as well as increased parasympathomimetic activity in the respiratory tract. In case of suspected asthma in athletes, the diagnostic procedures should include history taking, physical examination, atopic origin assessment and functional evaluation of the respiratory system. Along with good history taking, the diagnosis of asthma should rely on the positive outcome of at least one of the following tests: reversibility test, exercise test or positive result of eucapnic voluntary hyperventilation with $\mathrm{CO}_{2}$-enriched air test, nonspecific bronchoprovocation test with methacholine, hypertonic saline or mannitol provocation test. The aim of successful asthma management includes: achieve-
TABLE 4. Examples of common $\beta_{2}$-mimetics

\begin{tabular}{|l|c|c|}
\hline Bambuterol & Indacaterol* & Ritodrine \\
\hline Brombuterol & Isoxsuprine & Salbutamo* $^{*}$ \\
\hline Cimaterol & Mabuterol & Salmeterol* $^{*}$ \\
\hline Cimbuterol & Mapenterol & Terbutaline* $^{*}$ \\
\hline Clenbuterol $^{\#}$ & Olodaterol* $^{*}$ & Tulobuterol* $^{*}$ \\
\hline Clenpenterol $^{*}$ & Pirbuterol $^{*}$ & Vilanterol $^{*}$ \\
\hline Fenoterol* & Procaterol & Zilpaterol $^{*}$ \\
\hline Formoterol* & Ractopamine & \\
\hline Higenamine* $^{*}$ & Reproterol* & \\
\hline
\end{tabular}

"The substance classified by WADA as an example of doping substances in the category of anabolic agents (S1), *the substance classified by WADA as an example of doping substances in the category of $\beta_{2}$-mimetics (S3).

ment and maintenance of symptoms control, prevention of exacerbation, maintenance of the respiratory function within normal range of parameters. Asthma is a respiratory tract inflammation so inhaled glucocorticosteroids should be applied as the basic medication in chronic therapy and $\beta$-adrenergic antagonists should never be used as monotherapy. The treatment of asthma in athletes should always take into account current anti-doping regulations. According to WADA regulations, treatment of diagnosed asthma in athletes is not considered as doping, contrary to any attempts to use anti-asthmatic medication in healthy athletes.

\section{CONFLICT OF INTEREST}

The authors declare no conflict of interest.

\section{REFERENCES}

1. Langdeau J, Turcotte H, Bowie D, et al. Airway hyperresponsiveness in elite athletes. Am J Respir Crit Care Med 2000; 161: 1479-84.

2. Sue-Chu M. Winter sports athletes: long-term effects of cold air exposure. Br J Sports Med 2012; 46: 397-401.

3. Voy R. The U.S. Olympic committee experience with exercise-induced bronchospasm, 1984. Med Sci Sports Exerc 1986; 18: 328-30.

4. Weiler J, Layton T, Hunt M. Asthma in united states olympic athletes who participated in the 1996 summer games. J Allergy Clin Immunol 1998; 102: 722-6.

5. Weiler J, Ryan III E. Asthma in united states olympic athletes who participated in the 1998 olympic winter games. J Allergy Clin Immunol 2000; 106: 267-71.

6. Bonini M, Gramiccioni C, Fioretti D, et al. Asthma, allergy and the olympics: a 12-year survey in elite athletes. Curr Opin Allergy Clin Immunol 2015; 15: 184-92.

7. Carlsen K, Anderson S, Bjermer L, et al. Exercise-induced asthma, respiratory and allergic disorders in elite athletes: epidemiology, mechanisms and diagnosis: Part $i$ of the report from the joint task 
force of the European Respiratory Society (ERS) and the European Academy of Allergy and Clinical Immunology (EAACI) in cooperation with GA2LEN. Allergy 2008; 63: 387-403.

8. Carlsen KH, Anderson S, Bjermer L, et al. Treatment of exercise-induced asthma, respiratory and allergic disorders in sports and the relationship to doping: Part ii of the report from the joint task force of e European Respiratory Society (ERS) and European Academy of Allergy and Clinical Immunology (EAACI) in cooperation with GA2LEN. Allergy 2008; 63: 492-505.

9. Carlsen KH, Kowalski M. Asthma, allergy, the athlete and the olympics. Allergy 2008; 63: 383-6.

10. Kurowski M, Jurczyk J, Krysztofiak H, Kowalski ML. Exercise-induced respiratory symptoms and allergy in elite athletes: allergy and asthma in polish olympic athletes (A2POLO) project within GA2LEN initiative. Clin Respir J 2016; 10: 231-8.

11. Burns J, Mason C, Mueller N, et al. Asthma prevalence in olympic summer athletes and the general population: an analysis of three european countries. Resp Med 2015; 109: 813-20.

12. Bernard A, Carbonnelle S, de Burbure C, et al. Chlorinated pool attendance, atopy, and the risk of asthma during childhood. Environ Health Perspect 2006; 114: 1567-73.

13. Bernard A, Carbonnelle S, Dumont X, Nickmilder M. Infant swimming practice, pulmonary epiuthelium integrity, and the risk of allergic and respiratory diseases later in childhood. Pediatrics 2007; 119: 1095-103.

14. Bernard A, Carbonnelle S, Michel O, et al. Lung hyperpermeability and asthma prevalence in schoolchildren: unexpected associations with the attendance at indoor chlorinated swimming pools. Occup Environ Med 2003; 60: 385-94.

15. Drobnic F, Freixa A, Casan P, et al. Assessment of chlorine exposure in swimmers during training. Med Sci Sports Exerc 1996; 28: 271-4.

16. Kennedy MD, Davidson WJ, Wong LE, et al. Airway inflammation, cough and athlete quality of life in elite female cross-country skiers: a longitudinal study. Scand J Med Sci Sports 2016; 26: 835-42.

17. Larsson K, Ohlsén P, Larsson L, et al. High prevalence of asthma in cross country skiers. Br Med J 1993; 307: 1326-9.

18. Porter EB. Common injuries and medical problems in singles figure skaters. Curr Sports Med Rep 2013; 12: 318-20.

19. Provost-Craig MA, Arbour KS, Sestili DC, et al. The incidence of exercise-induced bronchospasm in competitive figure skaters. J Asthma 1996; 33: 67-71.

20. Stensrud T, Mykland K, Gabrielsen K, Carlsen K. Bronchial hyperresponsiveness in skiers: field test versus methacholine provocation? Med Sci Sports Exerc 2007; 39: 1681-6.

21. Vergès S, Flore P, Blanchi MP, Wuyam B. A 10-year follow-up study of pulmonary function in symptomatic elite cross-country skiers athletes and bronchial dysfunctions. Scand J Med Sci Sports 2004; 14: 381-7.

22. Couto M, Kurowski M, Moreira A, et al. Mechanisms of exercise-induced bronchoconstriction in athletes: current perspectives and future challenges. Allergy 2018; 73: 8-16.

23. Carbonnelle S, Francaux M, Doyle I, et al. Changes in serum pneumoproteins caused by short-term exposures to nitrogen trichloride in indoor chlorinated swimming-pools. Biomarkers 2002; 7: 464-78.

24. Kurowski M, Jurczyk J, Jarzębska M, et al. Association of serum clara cell protein $\mathrm{cc} 16$ with respiratory infections and immune response to respiratory pathogens in elite athletes. Respir Res 2014; 15: 45 .

25. Romberg K, Bjermer L, Tufvesson E. Exercise but not mannitol provocation increases urinary clara cell protein (cc16) in elite swimmers. Resp Med 2011; 105: 31-6.
26. Seys SF, Feyen L, Keirsbilck S, et al. An outbreak of swimming-pool related respiratory symptoms: an elusive source of trichloramine in a municipal indoor swimming pool. Int J Hyg Environ Health 2015; 218: 386-91.

27. Seys SF, Hox V, Van Gerven L, et al. Damage-associated molecular pattern and innate cytokine release in the airways of competitive swimmers. Allergy 2015; 70: 187-94.

28. Larsson L, Hemminqsson P, Boëthius G. Self-reported obstructive airway symptoms are common in young cross-country skiers. Scand J Med Sci Sports 1994; 4: 124-7.

29. Couto M, Silva D, Santos P, et al. Exploratory study comparing dysautonomia between asthmatic and non-asthmatic elite swimmers. Rev Port Pneumol 2015; 21: 22-9.

30. Stang J, Stensrud T, Mowinckel P, Carlsen K. Parasympathetic activity and bronchial hyperresponsiveness in athletes. Med Sci Sports Exerc 2016; 48: 2100-7.

31. Moreira A, Delgado L, Carlsen K. Exercise-induced asthma: why is it so frequent in olympic athletes? Expert Rev Respir Med 2011; 5: $1-3$.

32. Bonini M, Palange P. Exercise-induced bronchoconstriction: new evidence in pathogenesis, diagnosis and treatment. Asthma Res Prac 2015; 1: 2.

33. Schwartz L, Delgado L, Craig T, et al. Exercise-induced hypersensitivity syndromes in recreational and competitive athletes: a practall consensus report (what the general practitioner should know about sports and allergy). Allergy 2008; 63: 953-61.

34. Miller MR, Crapo R, Hankinson J, et al. General considerations for lung function testing. Eur Respir J 2005; 26: 153-61.

35. Miller MR, Hankinson J, Brusasco V, et al. Standardisation of spirometry. Eur Respir J 2005; 26: 319-38.

36. Cockcroft D. Direct challenge tests. Airway hyperresponsiveness in asthma: its measurement and clinical significance. Chest 2010; 138: 18S-24S.

37. Rundell K, Slee J. Exercise and other indirect challenges to demonstrate asthma or exercise-induced bronchoconstriction in athletes. J Allergy Clin Immunol 2008; 122: 238-46.

38. Weiler J, Bonini S, Coifman R, et al. American Academy of Allergy, Asthma \& Immunology Work Group report: exercise-induced asthma. J Allergy Clin Immunol 2007; 119: 1349-58.

39. Crapo R, Casaburi R, Coates A, et al. Guidelines for methacholine and exercise challenge testing-1999. Am J Resp Crit Care Med 2000; 161: 309-29.

40. Carlsen K, Engh G, Mørk M. Exercise-induced bronchoconstriction depends on exercise load. Respir Med 2000; 94: 750-5.

41. Taylor D. Nitric oxide as a clinical guide for asthma management. J Allergy Clin Immunol 2006; 117: 259-62.

42. Gina Report, Global Strategy for Asthma Management and Prevention. Updated 2011. http://www.Ginasthma.Org/uploads/users/ files/gina_report2011_may4.pdf [accessed 23 June 2012].

43. Couto M, Stang J, Horta L, et al. Two distinct phenotypes of asthma in elite athletes identified by latent class analysis. J Asthma 2015; 52: 897-90.

44. Fitch K. An overview of asthma and airway hyper-responsiveness in olympic athletes. Br J Sports Med 2012; 46: 413-6.

45. Hoshino Y, Koya T, Kagamu H, et al. Effect of inhaled corticosteroids on bronchial asthma in Japanese athletes. Allergol Int 2015; 64: 145-9.

46. Duong M, Amin R, Baatjes A, et al. The effect of montelukast, budesonide alone, and in combination on exercise induced bronchoconstriction. J Allergy Clin Immunol 2012; 130: 535-9. 
47. Rundell K, Spiering B, Baumann J, Evans T. Bronchoconstriction provoked by exercise in a high-particulatematter environment is attenuated by montelukast. Inhal Toxicol 2005; 17: 99-105.

48. Villaran C, O’Neill S, Helbling A, van Noord J. Montelukast versus salmeterol in patients with asthma and exercise-induced bronchoconstriction. Montelukast/salmeterol exercise study group. J Allergy Clin Immunol 1999; 104: 547-53.

49. Edelman J, Turpin J, Bronsky E, et al. Oral montelukast compared with inhaled salmeterol to prevent exercise-induced bronchoconstriction. A randomized, double-blind trial. Exercise study group. Ann Intern Med 2000; 132: 97-104.

50. Levenson M. Long-acting beta-agonists and adverse asthma events meta-analysis. FDA Briefing Material November 12, 2008.

51. Hancox R, Subbarao P, Kamada D, et al Beta2-agonist tolerance and exercise-induced bronchospasm. Am J Resp Crit Care Med 2002; 165: 1068-70.

52. Muraro A, Roberts G. EAACI Allergen Immunotherapy Guidelines. EAACI, Zurych 2017.

53. Zielen S, Kardos P, Madonini E. Steroid-sparing effects with allergen-specific immunotherapy in children with asthma: a randomized controlled trial. J Allergy Clin Immunol 2010; 126: 942-9.

54. Spooner C, Spooner G, Rowe B. Mast-cell stabilizing agents to prevent exercise induced bronchoconstriction. Cochrane Database Syst Rev 2003; 4: CD002307.

55. Gałązka-Franta A, Jura-Szołtys E, Smółka W, Gawlik R. Upper respiratory tract diseases in athletes in different sports disciplines. J Hum Kinet 2016; 53: 99-106.

56. Gleeson M, Pyne D. Respiratory inflammation and infections in high-performance athletes. Immunol Cell Biol 2016; 94: 124-31.

57. Price O, Hull J, Howatson G, et al. Vitamin D and omega-3 polyunsaturated fatty acid supplementation in athletes with exercise-induced bronchoconstriction: a pilot study. Expert Rev Respir Med 2015; 9: 369-78.

58. Price O, Hull J. Asthma in elite athletes: Who cares? Clin Pulm Med 2014; 21: 68-75.

59. Beuther D, Martin R. Efficacy of a heat exchanger mask in cold exercise-induced asthma. Chest 2006; 129: 1188-93.

60. Turowski D, Kończak D, Michalak D, Pokrywka A. Zasady postępowania w astmie i nadreaktywności oskrzeli u sportowców wyczynowych. Alergia Astma Immunol 2014; 19: 135-43.

61. The World-Anti Doping Code, International Standard, Prohibited List, january 2018. World Anti-Doping Agency.

62. Kaliszewski P, Kończak D, Chołbiński P, et al. Budesonide treatment of professional athletes and anti-doping testing - case studies. Acta Pol Pharm 2016; 73: 229-37.

63. Görgens C, Guddat S, Thomas A, et al. Simplifying and expanding analytical capabilities for various classes of doping agents by means of direct urine injection high performance liquid chromatography high resolution/high accuracy mass spectrometry. J Pharm Biomed Anal 2016; 131: 482-96.

64. Bai G, Yang Y, Shi Q, et al. Identification of higenamine in radix aconiti lateralis preparata as a beta2-adrenergic receptor agonist. Acta Pharmacol Sin 2008; 29: 1187-94.

65. Jeter J, DeZee K, Kennedy L. A case of paraspinal muscle rhabdomyolysis in a 22-year-old male after ingesting a supplement containing higenamine. Mil Med 2015; 180: e847-9. 